\title{
Histopathologic changes in ascending aorta and risk factors related to histopathologic conditions and aortic dilatation in patients with tetralogy of Fallot
}

\author{
Ujjwal K. Chowdhury, MCh, Diplomate NB, ${ }^{a}$ Anand K. Mishra, MS, ${ }^{a}$ Ruma Ray, MD, MRC (Path), ${ }^{b}$
}

Mani Kalaivani, MSc (Biostatistics), ${ }^{\mathrm{c}}$ Srikrishna M. Reddy, $\mathrm{MS}^{\mathrm{a}}$ and Panangipalli Venugopal, $\mathrm{MCh}^{\mathrm{a}}$

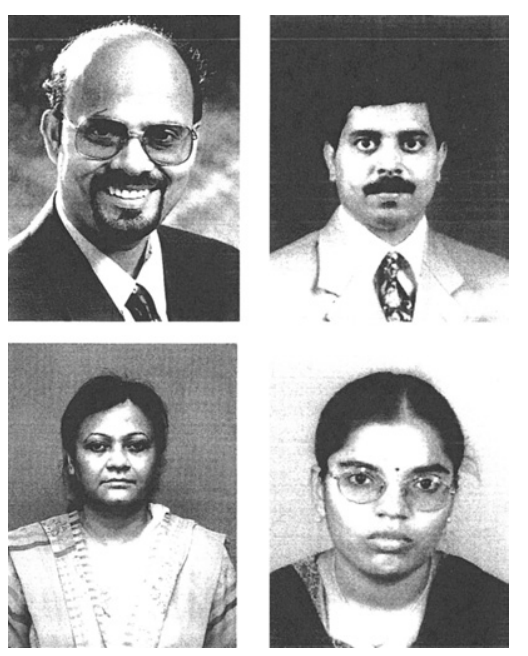

Drs Chowdhury and Mishra (upper panel, left to right); Drs Ray and Kalaivani (lower panel, left to right)

Supplemental material is available online.
From the Departments of Cardiothoracic Surgery, ${ }^{\mathrm{a}}$ Cardiac Pathology, ${ }^{\mathrm{c}}$ and Biostatistics, ${ }^{c}$ All India Institute of Medical Sciences, New Delhi, India.

Received for publication Feb 6, 2007; revisions received May 19, 2007; accepted for publication June 1, 2007.

Address for reprints: Dr. Ujjwal K Chowdhury, Additional Professor, Department of Cardiothoracic and Vascular Surgery, All India Institute of Medical Sciences, New Delhi-110029, India; (E-mail: ujjwalchow@rediffmail.com ujjwalchowdhury@gmail.com).

J Thorac Cardiovasc Surg 2008;135:69-77

$0022-5223 / \$ 34.00$

Copyright @ 2008 by The American Association for Thoracic Surgery

doi:10.1016/j.jtcvs.2007.06.011
Objective: The purposes of this study were to evaluate the histologic characteristics of the aortic wall and the risk factors related to histopathology and aortic dilatation in patients undergoing intracardiac repair of tetralogy of Fallot.

Methods: Operatively excised full-thickness aortic wall tissue from 98 consecutive patients undergoing intracardiac repair of tetralogy of Fallot aged 6 months to 47 years (mean $104.5 \pm 102.8$ months; median 72 months) were studied by light microscopy. The receiver operating characteristic curve analysis was done to quantify the diagnostic accuracy of loss of lamellar counts and multiple logistic regression models.

Results: Twenty-five (25.5\%) aortic tissue specimens were indicated as histologically normal and were used as normal controls. The incidence of elastic fragmentation, increased ground substance, medionecrosis, smooth muscle disarray, and fibrosis was $74.5 \%, 54 \%, 39.8 \%, 26.5 \%$, and $57.1 \%$, respectively. A lamellar count of less than 60 was associated with a sensitivity of $80 \%$ and a specificity of $87.67 \%$. Area under the receiver operating characteristic curve indicated that $93.37 \%$ (standard error \pm 0.039$)$ of the time the value of lamellar count was lower for the abnormal histopathology group than for the normal group $(P<.001)$. The risk of aortic dilatation was 15.97 times higher in patients with histopathologically abnormal aorta.

Conclusions: The majority of aortic media of the ascending aorta in cyanotic tetralogy of Fallot indicates significant loss of lamellar units and pre-existing intrinsic aortopathy. The changes are present since infancy and are more pronounced in older patients subjected to long-standing cyanosis and volume overload and may account for or may coexist with the higher incidence of aortic dilatation encountered in these patients.

$\mathrm{D}$ ilatation of the aortic root with or without aortic regurgitation is a welldescribed feature in patients with tetralogy of Fallot (TOF) and pulmonary stenosis or pulmonary atresia. ${ }^{1-3}$ A subset of adult patients with TOF exhibit ongoing dilatation of the aortic root even after repair, necessitating aortic valve and aortic root surgery. ${ }^{1-7}$ It is hypothesized that a medial abnormality coupled with increased aortic blood flow might be the cause for aortic root dilatation in untreated patients..$^{2-4,6,8-13}$ However, histopathologic or ultrastructural studies to lend credence to this hypothesis have been limited because of limited number of patients and restricted observations. ${ }^{1,7-13}$

This prospective study aims to (1) elucidate the histopathologic characteristics of the aortic wall in patients with TOF and to identify the relationship, if any, between the lamellar counts and appearance of histopathologic changes; (2) correlate any identifiable pathologic changes with known risk factors such as age at operation, 


$$
\begin{aligned}
& \text { Abbreviations and Acronyms } \\
& \begin{aligned}
\text { CI } & =\text { confidence interval } \\
\text { MAPCA } & =\text { major aortopulmonary collateral artery } \\
\text { OR } & =\text { odds ratio } \\
\text { ROC } & =\text { receiver operating characteristic } \\
\text { RVEDP } & =\text { right ventricular end-diastolic pressure } \\
\text { SD } & =\text { standard deviation } \\
\text { SE } & =\text { standard error } \\
\text { TOF } & =\text { tetralogy of Fallot }
\end{aligned}
\end{aligned}
$$

previous systemic-pulmonary arterial shunting procedures, systemic arterial oxygen saturation, hematocrit, right ventricular end-diastolic pressure (RVEDP), degree of aortic override, and aortic regurgitation; (3) identify the histopathologic characteristics that may predispose patients to the higher risk of aortic dilatation seen in these patients; and finally (4) to evaluate the sensitivity, specificity, and predictive accuracy of a low lamellar count as a possible predictor of histopathologically abnormal aorta.

\section{Patients and Methods}

Patients were enrolled for this prospective study after approval by the institutional ethics committee and after informed written consent had been obtained from parents/guardians. Between January 2004 and June 2006, specimens of excised aortic wall from 108 consecutive patients undergoing intracardiac repair for TOF at AIIMS, New Delhi, India, were subjected to histopathologic analysis. Of these, 98 samples from 98 patients ( 71 male subjects) were found suitable for analysis (10 were excluded either because of insufficient tissue material or because of morphologic artifacts resulting from inadequate fixation and/or poor orientation). The examiners were blind to demographic, procedural, and hemodynamic data.

Age at correction was 6 months to 47 years (mean $104.5 \pm$ 102.8 months; median 72 months), with $30.6 \%$ of patients $(n=30)$ being younger than 4 years of age and $20.4 \%(n=20)$ being older than 12 years of age. Cardiac catheterization and angiocardiography were performed on all patients to confirm the diagnosis, to define coronary artery anatomy, and to identify major aortopulmonary collateral arteries (MAPCAs). The details of the patients are summarized in Table E1. In $65(66.3 \%)$ patients, the aortic root was dilated. Dilatation was defined as the ratio of observed/ expected aortic root diameter indexed to body surface area and age greater than 1.5. ${ }^{14}$ Thirteen (20\%) of 65 patients had evidence of trivial to mild aortic regurgitation.

Standard cardiopulmonary bypass and myocardial protection techniques were used in all patients. Intracardiac repair was performed with a transatrial, transpulmonary approach in $76(77.5 \%)$ patients and a trans-right atrial approach in $22(22.5 \%)$ patients. In $65(66.3 \%)$ patients, a transannular patch was used. Five (5.1\%) patients with TOF and pulmonary atresia required a right ventricle-pulmonary artery homograft conduit. The aortic tissues studied were operatively excised from the aortic cannulation site. A button of full-thickness aortic wall tissue (about $2-3 \mathrm{~mm}$ width) was excised from within the aortic purse-string suture on a side-biting aortic clamp as atraumatically as possible.

\section{Collection and Preparation of Tissues}

Excised full-thickness aortic wall tissue during intracardiac repair was subjected to histopathologic evaluation by light microscopy.

\section{Light Microscopic Evaluation}

Each biopsy specimen was fixed in 10\% buffered formalin solution at room temperature, embedded in paraffin block, and thin sections of 4 to $5 \mu \mathrm{m}$ were taken. The slides were then stained with hematoxylin and eosin. Special stains like Masson trichrome, elastic Verhoeff van Gieson, and alcian blue periodic acid-Schiff were used as and when indicated. The sections were examined with research light microscope (Nikon Optiphot; Nikon Corporation, Tokyo, Japan, magnification $40 \times, 100 \times$, or $200 \times$ ).

The histopathology slides were simultaneously evaluated by two independent observers and there was no interobserver disagreement on interpretation of the presence or absence of disease. The histologic evaluation of the aortic media included 6 variables: (1) lamellar count, (2) loss or fragmentation of elastic lamellae, (3) increased amount of ground substance, (4) medionecrosis, (5) smooth muscle disarray (changes in smooth muscle orientation), and (6) fibrosis. The lesions were graded 1 to 3 according to the criteria adapted from Schlatmann and Becker ${ }^{15}$ and from de Sa and associates ${ }^{16}$ (Table E2).

The grades were determined on the basis of the worst area observed in each specimen. The number of elastic lamellae were counted at the thickest and thinnest area in the media and the mean of these numbers was calculated. While counting, we included the longer elastic lamellae parallel to the lumen.

\section{Definitions}

Aortic root dilatation. Age, height, body weight, and sex are known to be the determinants of aortic root dimensions in the normal heart. ${ }^{14,17}$ Therefore, we used the standard nomogram for aortic root size at the sinotubular junction adopted from Roman and associates, ${ }^{14}$ indexed to body surface area and age. ${ }^{5,16,17}$ Aortic root dilatation was defined as the ratio of observed/expected aortic root diameter greater than 1.5 .

Apoptosis. Apoptosis is defined as a form of programmed cell death and has been recognized as a central feature of fundamental biological processes including embryonic morphogenesis, remodeling of mature tissues, and cell replacement in certain adult tissues, for example, the thymus. In contrast to necrosis, apoptosis occurs in isolated cells without any accompanying cellular reaction. ${ }^{18-20}$

Elastic fragmentation. Elastic fragmentation is defined as focal fragmentation of elastic lamellae in the aortic media. Three grades were recognized: grade 1 , fewer than 5 foci of elastic lamellae, loss or fragmentation in one microscopic field, each focus comprising 2 to 4 neighboring elastic lamellae; grade 2, 5 to 9 foci of elastic lamellae fragmentation in one microscopic field; and grade 3 , presence of 10 or more foci of elastic fragmentation in one microscopic field (Table E2). ${ }^{15,16}$

Accumulation of ground substance. The ground substance is a hydrated gel composed of glycosaminoglycans, proteoglycans, and adhesive glycoproteins in which elastic fibers and collagen are 
embedded. ${ }^{15,21}$ Accumulation of ground substance was characterized by a noninflammatory loss of smooth muscle cells in the presence of intact elastic lamellae and fragmented elastic fibers. There was mucoid degeneration with no identifiable cystic wall. ${ }^{10,15,21}$

In grade 1, there were mild fragmentation of elastic fibers with mild increase in ground substance and little or no change in smooth muscle; in grade 2, there were widespread fragmentation of elastic fibers, further increase in ground substance, and widespread loss of smooth muscle; and in grade 3, there were large areas of complete loss of elastic fibers and smooth muscle and large areas of ground substance accumulation (Table E2). ${ }^{15,16}$

Medionecrosis. Medionecrosis is defined as a focal loss of smooth muscle nuclei in the media. Three grades were recognized (Table E2).

Smooth muscle disarray (changes in smooth muscle orientation). Three grades were recognized: grade 1, smooth muscle disarray involving less than one third of the thickness of the media; grade 2 , smooth muscle disarray involving one third to one half of the thickness of the media; and grade 3, large area of smooth muscle disarray involving more than one half of media thickness, associated with elastic fragmentation (Table E2).

Fibrosis. Fibrosis is defined as an increase in interstitial collagen. Three grades were recognized (Table E2).

\section{Statistical Methods and Analysis}

Statistical analysis was carried out with Intercooled STATA 9.0 software (Stata, College Station, Tex). Interval-related data were expressed as mean \pm standard deviation (SD) and categorical variables were expressed as percentages. The difference in proportions was tested with the $\chi^{2}$ test.

The receiver operating characteristic (ROC) curve analysis was done to determine the cutoff value of the lamellar count, which will predictably separate normal from the abnormal considering aortic dilatation as the outcome and taking histopathology as the gold standard. To quantify the predictive accuracy of the lamellar count, we analyzed the area under the ROC curve.

Aortic tissue specimens without histologic abnormalities were defined as normal and were used as normal controls. The simple logistic regression followed by forward stepwise multiple logistic regression analysis was used to identify the independent risk factors associated with the pathologic features and aortic dilatation. The predictive accuracy of the multiple logistic regression model was assessed using area under the ROC curve. The results were expressed as odds ratio (OR) and $95 \%$ confidence interval (CI) for each independent variable.

\section{Results}

There were $3(3.1 \%)$ perioperative deaths resulting from massive pulmonary bleeding $(\mathrm{n}=2)$ and low output syndrome and multiorgan failure $(\mathrm{n}=1)$. All patients were routinely started on dopamine $\left(4 \mu \mathrm{g} \cdot \mathrm{kg}^{-1} \cdot \min ^{-1}\right)$ to increase renal perfusion and sodium nitroprusside $(0.5 \mu \mathrm{g}$. $\left.\mathrm{kg}^{-1} \cdot \min ^{-1}\right)$ to reduce afterload. Patients considered to have low output syndrome $(n=46)$ required dopamine, dobutamine, epinephrine, and milrinone either isolated or in combination. Median duration of inotropic requirement was
7 days (range 7-10 days) in these patients. Postoperatively, digoxin, diuretics, and angiotensin-converting enzyme inhibitors were weaned at varying time intervals. There was no late death.

\section{Follow-up}

Survivors $(\mathrm{n}=95)$ underwent clinical examination, electrocardiogram, and echocardiogram every 3 months. Follow-up was $100 \%$ complete (range 1-36 months) and yielded 191.03 patient-years of data with a mean follow-up time of 24.13 months ( \pm SD 9.99; range 1-36 months). The actuarial survival at 36 months was $96.94 \% \pm 0.01 \%(95 \%$ CI 0.90-0.99). At their last follow-up, 93 (97.9\%) patients were in New York Heart Association functional classes I and II. Only $2(2.1 \%)$ patients were receiving diuretics and vasodilators late postoperatively and were in New York Heart Association class III. Reoperation or reintervention was not required for any patient.

\section{Echocardiographic Evaluation}

The left ventricular function was normal (ejection fraction $>0.5)$ in 88 patients and depressed in 7 patients. Fifty-three $(55.7 \%)$ patients had mild and $12(12.6 \%)$ patients had moderate pulmonary regurgitation. Postoperatively, the mean indexed aortic diameter was $25.90 \pm 10.21 \mathrm{~mm} / \mathrm{m}^{2}$ (range $0-68 \mathrm{~mm} / \mathrm{m}^{2}$; median $24.0 \mathrm{~mm} / \mathrm{m}^{2}$ ). All patients ( $=65$ ) with a preoperatively dilated aorta continued to have indexed aortic dimensions measuring between 24.80 and 32 $\mathrm{mm}$. There was no progression of aortic dilatation or aortic regurgitation in these patients.

\section{Histopathologic and Risk Factor Analysis}

Twenty-five $(25.5 \%)$ aortic tissue specimens were found to be histologically normal and were used as controls. These specimens exhibited layers of longitudinally arranged elastic lamellae interspersed with smooth muscle cells and collagen fibrils in a mucopolysaccharide ground substance (Figure E1, $A$ and $B$ ).

Since both pathologists agreed in saying 73 abnormal histopathologic specimens as abnormal and 25 normal aortic tissue sections as normal, the Kappa value is 1.00. Elastic fragmentation, increased ground substance, medionecrosis, smooth muscle disarray, and fibrosis were present in 73 (74.5\%), $53(54 \%), 39(39.8 \%), 26(26.5 \%)$, and $56(57.1 \%)$ specimens, respectively.

\section{Relationship Between Aortic Root Dilatation and Histologic Abnormalities, Including Other Candidate Variables}

Aortic diameter measured echocardiographically in our study showed significant dilatation in $66.3 \%(n=65)$ of patients with TOF. To assess the risk factors related to aortic root dilatation in TOF, we took into consideration aorta with and without histologic abnormalities and other candidate 
TABLE 1. Predictors of aortic dilatation by stepwise multiple logistic regression analysis applied to all 98 patients

\begin{tabular}{lcr}
\hline Variables (covariates adjusted) & OR (95\% CI) & $\boldsymbol{P}$ value \\
\hline 1. Histopathologically abnormal aorta & $15.97(3.07-83.15)$ & .001 \\
2. Elastic fragmentation & $15.97(3.07-83.15)$ & .001 \\
3. Increased ground substance & $4.86(1.16-20.28)$ & .003 \\
4. Male sex & $12.74(4.46-36.42)$ & $<.001$ \\
5. Aortic override $>50 \%$ & $10.50(1.30-82.69)$ & .001 \\
6. Double-outlet right ventricle & $5.94(1.36-26.01)$ & .02
\end{tabular}

$O R$, Odds ratio; $\mathrm{Cl}$, confidence interval.

variables. Aortic tissue specimens without histologic abnormalities $(n=25)$ were defined as normal and were used as the control group. It is noteworthy that of 65 patients with aortic root dilatation, $62(95.4 \%)$ patients exhibited histologic abnormalities and $3(4.6 \%)$ patients were histologically normal (Tables 1 and E3).

The presence of elastic fragmentation, increased ground substance, medionecrosis, muscle disarray, fibrosis, age older than 96 months, male sex, systemic arterial desaturation $(<80 \%)$, hematocrit greater than $45 \%$, aortic override greater than $50 \%$, presence of aortic regurgitation, higher RVEDP $(>12 \mathrm{~mm} \mathrm{Hg}$ ) of the MAPCA, right aortic arch, double-outlet right ventricle, and TOF with pulmonary atresia were independent risk factors for aortic root dilatation according to bivariate analysis (Table E3).

Logistic regression analysis identified histopathologically abnormal aorta, elastic fragmentation, increased ground substance, male sex, degree of aortic override greater than $50 \%$, and double-outlet right ventricle as the predictors for aortic dilatation in this study. The risk of aortic dilatation was 15.97 times higher (95\% CI 3.0783.15 ) in patients with histopathologically abnormal aorta. The predictive accuracy of the logistic regression model for aortic root dilatation was assessed by the area under the ROC curve, and the value in this cohort was $92.4 \%$ (Table 1, Figure 1).

\section{Relationship Between the Lamellar Count and Histologically Abnormal Aorta}

Analysis of ROC curve. The mean lamellar counts in this cohort with and without histologic abnormalities (control group) were 40.85 ( \pm SD 11.04; range 15-59) and 66.72 ( \pm SD 4.69; range 60-76), respectively. By pairwise comparisons, the differences in lamellar count of both groups of patients were statistically significant $(P<.0001)$. A mean lamellar count of 40.85 ( \pm SD 11.04, range 15-59) was always associated with a histologically abnormal aorta and aortic dilatation $(\mathrm{OR}=7.46$ [95\% CI 2.85-19.58]; $P<$ $.0001)$.

With a lamellar count of 60 as the optimal cutoff point for abnormal aortic histopathology in patients undergoing

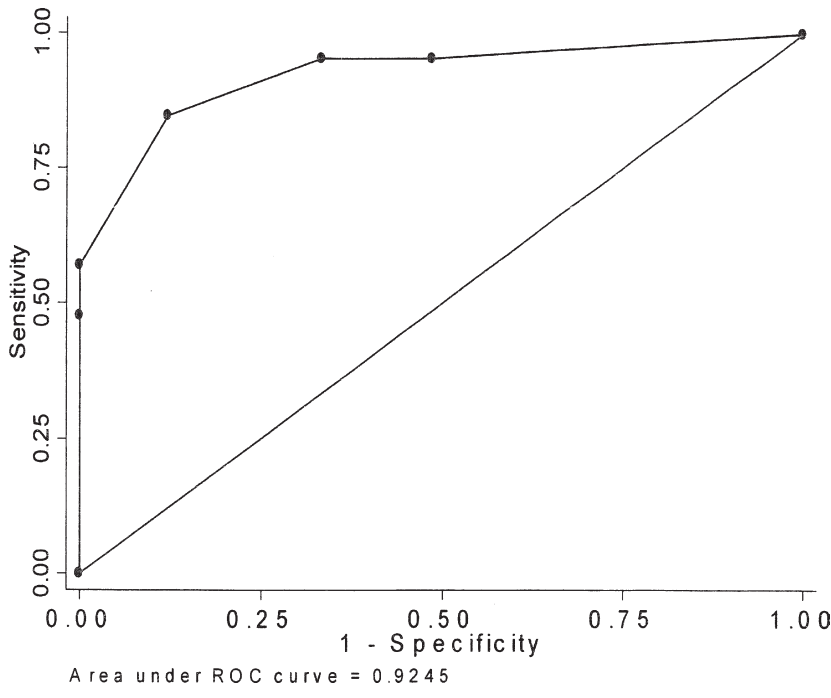

Figure 1. The receiver operating characteristic $(\mathrm{ROC})$ curve of the patients in the study group to determine the predictive accuracy of the model after logistic regression was assessed using the area under the ROC curve.

intracardiac repair of TOF, the sensitivity was $80 \%$ and the specificity was $87.67 \%$. The predictive accuracy of a positive or negative result was $68.7 \%$ and $92.3 \%$, respectively (Table 2).

Area analysis under the ROC curve indicated that $93.37 \%$ (standard error $[\mathrm{SE} \pm 0.0 .024 ; 95 \% \mathrm{CI}=0.88$ 0.98 )] of the time, the values of lamellar count were lower for patients with aortic dilatation in patients undergoing intracardiac repair of TOF as compared with abnormal histopathology, which is highly significant $(P<.001)$ (Figure 2).

\section{Elastic Fragmentation}

Seventy-three $(74.5 \%)$ specimens had elastic tissue fragmentation. It was graded as moderate (grade 2) in 27 $(27.5 \%)$ and severe in $23(23.5 \%)$ specimens. Logistic re-

TABLE 2. Sensitivity, specificity, and predictive accuracy of lamellar count $(<60)$ for an abnormal aortic histopathologic condition in patients undergoing intracardiac repair of tetralogy of Fallot $(n=98)$

\begin{tabular}{lccc}
\hline & \multicolumn{3}{c}{ Abnormal aortic histopathology } \\
\cline { 2 - 4 } Lamellar count & Yes & No & Total \\
\hline Yes & 20 (TP) & 9 (FP) & 29 \\
No & 5 (FN) & 64 (TN) & 69 \\
Total & 25 & 73 & \\
\hline
\end{tabular}

Sensitivity $(\%)=20 / 25=80 \%$; specificity $(\%)=64 / 73=87.7 \%$; $(+)$ test predictive value $(\%)=68.7 \% ;(-)$ test predictive value $=92.3 \%$. FN, False negative; FP, false positive; TN, true negative; TP, true positive. 


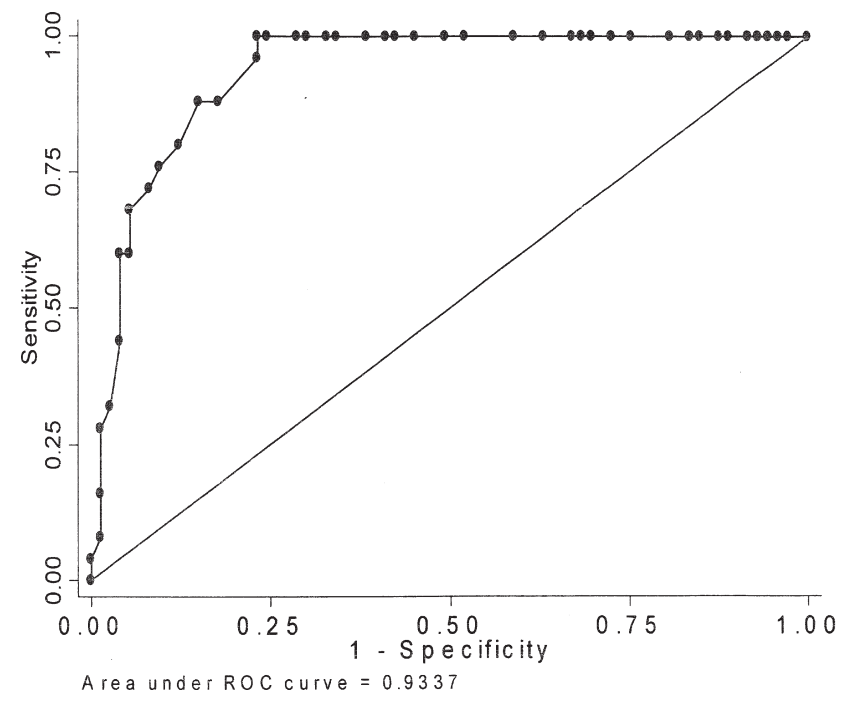

Figure 2. The receiver operating characteristic (ROC) curve of the study group to compare the trade-offs between the true-positive rate and the false-positive rate of low lamellar count. A lamellar count of 60 as the optimal cutoff point for an abnormal histopathologic condition in patients undergoing intracardiac repair with a sensitivity of $\mathbf{8 0} \%$ and specificity of $\mathbf{8 7 . 7} \%$.

gression analysis accounting for the effects of other variables identified age older than 96 months, systemic arterial desaturation $(<80 \%)$, aortic override $(>50 \%)$, and presence of MAPCAs as significant predictors for elastic fragmentation. It is noteworthy that lamellar loss and elastic fragmentation up to grade 2 severity were noted in $45.5 \%(\mathrm{n}=5)$, $36.9 \%(\mathrm{n}=7)$, and $43.5 \%(\mathrm{n}=10)$ specimens at 24,48 , and 72 months of age, respectively (Tables 3 and E4; Figures E2, $A, B$ and E3, $A$ to $F$ ).

\section{Increased Amount of Ground Substance}

A total of $53(54.1 \%)$ specimens had excessive deposition of ground substance. Its incidence was higher in older age groups ( $>96$ months) and in patients with systemic arterial desaturation $(<80 \%)$ and higher RVEDP $(>12 \mathrm{~mm} \mathrm{Hg})$ (Tables 3 and E4 and Figure E4, $A$ to $D$ ).

\section{Medionecrosis}

Medionecrosis was exhibited by $39.8 \%(n=39)$ of aortic tissue specimens. Patients undergoing previous palliative systemic-pulmonary arterial shunting procedures and those having higher RVEDP, increased indexed aortic diameter, aortic override greater than 50\%, and presence of MAPCAs were found to be at increased risk for the development of medionecrosis (Tables 3 and E4 and Figure E4, $A$ to $D$ ).

\section{Muscle Disarray}

Smooth muscle disarray of grade 3 severity was seen in $26.5 \%(n=26)$ of aortic tissue specimens. All these
TABLE 3. Risk factors for elastic fragmentation, increased ground substance, medionecrosis, muscle disarray, and fibrosis in aortic tissue of TOF by forward stepwise logistic regression analysis

\begin{tabular}{|c|c|c|}
\hline Variables & Risk ratio $(95 \% \mathrm{CI})$ & $P$ value \\
\hline \multicolumn{3}{|l|}{ Elastic fragmentation $(\mathrm{n}=73$ ) } \\
\hline $\mathrm{Age}^{*}$ & $36.28(1.84-715.05)$ & .02 \\
\hline Systemic arterial oxygen saturation* & $35.36(2.80-55.80)$ & .002 \\
\hline Aortic override* & $35.13(8.83-140.01)$ & .002 \\
\hline Indexed aortic diameter* & $43.56(30.45-170.72)$ & $<.001$ \\
\hline MAPCAs* & $0.056(0.003-0.909)$ & .04 \\
\hline \multicolumn{3}{|c|}{ Increased ground substance $(n=53)$} \\
\hline $\mathrm{Age}^{*}$ & $4.13(0.97-17.55)$ & .05 \\
\hline Systemic arterial oxygen saturation* & $54.69(5.89-147.40)$ & $<.001$ \\
\hline RVEDP* & $23.67(16.99-240.56)$ & $<.001$ \\
\hline \multicolumn{3}{|l|}{ Medionecrosis $(\mathrm{n}=39)$} \\
\hline Previous palliation* & $191.79(7.18-512.18)$ & .002 \\
\hline RVEDP* & $99.35(5.28-191.54)$ & .01 \\
\hline Indexed aortic diameter* & $180.93(5.78-566.96)$ & .003 \\
\hline Aortic override* & $86.83(6.55-189.42)$ & .001 \\
\hline MAPCAs* & 4.67 (1.02-29.19) & .047 \\
\hline \multicolumn{3}{|l|}{ Muscle disarray $(\mathrm{n}=26)$} \\
\hline $\mathrm{Age}^{*}$ & $335.48(27.18-697.15)$ & .001 \\
\hline Aortic override* & $54.97(5.08-293.79)$ & .001 \\
\hline \multicolumn{3}{|l|}{ Fibrosis $(n=56)$} \\
\hline $\mathrm{Age}^{*}$ & $14.45(1.19-175.49)$ & .04 \\
\hline Systemic arterial oxygen saturation* & $38.48(2.63-562.42)$ & .01 \\
\hline Hematocrit* & $19.04(1.54-235.16)$ & .02 \\
\hline Aortic override* & $12.50(1.37-113.83)$ & .02 \\
\hline Indexed aortic diameter* & $115.53(7.44-792)$ & .001 \\
\hline Aortic regurgitation* & $121.47(5.10-322.14)$ & .01 \\
\hline MAPCAs* & $12.31(0.94-161.08)$ & .05 \\
\hline Previous palliation* & $20.91(1.92-227.63)$ & .01 \\
\hline Right aortic $\operatorname{arch}^{*}$ & $23.87(1.33-426.96)$ & .03 \\
\hline
\end{tabular}

Cl, Confidence interval; MAPCA, major aortopulmonary collateral artery; RVEDP, right ventricular end-diastolic pressure, TOF, tetralogy of Fallot. *Variables with higher risk.

patients showed grade $2(\mathrm{n}=3)$ to grade $3(\mathrm{n}=23)$ elastic fragmentation. Age older than 96 months and aortic override greater than $50 \%$ were independent risk factors for its development (Tables 3 and E4 and Figure E5, $A$ to $D$ ).

\section{Fibrosis}

Fibrosis was exhibited by $57.1 \%(\mathrm{n}=56)$ of aortic biopsy specimens. Older age groups ( $>96$ months), systemic arterial desaturation $(<80 \%)$, higher hematocrit $(>45 \%)$, aortic override greater than $50 \%$, increased indexed aortic diameter, presence of aortic regurgitation, MAPCAs, previous systemic-pulmonary arterial shunting procedures, and right aortic arch were identified as significant predictors for the development of fibrosis (Tables 3 and E4 and Figure E6, $A$ to $D$ ). 


\section{Discussion}

So far as we are aware, there have been only 3 published studies (autopsy series, $\mathrm{n}=2$; surgical series, $\mathrm{n}=1$ ) in the literature addressing specifically the existence of intrinsic aortopathy in patients with TOF. ${ }^{9,11,12}$ However, these publications have not assessed the interrelationship of specific histopathologic findings with the potential influencing factors. The major findings of this study include the existence of histologically normal aorta in only $25.5 \%$ of aortic tissue specimens and the presence of several intrinsic degenerative pathologic characteristics of varying grades of severity. Other important findings are significant loss of lamellar counts and the prevalence of intrinsic histologic abnormalities of the aortic wall in patients as early as 6 months of age (Tables 1 to 3 and E3).

\section{What Are the Potential Risk Factors Relating to Aortic Dilatation in TOF?}

The literature documents up to $15 \%$ incidence of aortic root dilatation in patients undergoing intracardiac repair for TOF. ${ }^{1-7}$ The aortic root dilatation is often progressive, with development of aortic regurgitation necessitating aortic valve replacement or repair, ${ }^{1-7,12,13}$ and has been reported to occur in patients not treated surgically ${ }^{2,4,6}$ as well as late after repair in patients treated surgically. ${ }^{1-7,10,12,13}$

Four variables have been incriminated as the potentially influencing factors for aortic dilatation: (1) abnormal morphogenesis resulting in unequal division of the fetal truncus, favoring aorta, (2) volume overload implicit in the biventricular aorta, (3) aortic regurgitation that augments volume overload and introduces pulsatile flow facilitating dilatation, and (4) intrinsic medial degenerative changes. ${ }^{1-6,10-12}$ In patients with TOF treated surgically, the cause of aortic root dilatation is thought to be predominantly secondary to chronic hemodynamic stress from volume overload of the aorta. ${ }^{3,7,11-13}$

Aortic diameter measured echocardiographically in our study showed significant dilatation in $66.3 \%$ of patients with TOF. It is noteworthy that of these 65 patients with dilated aorta, 62 (95.4\%) exhibited histologic abnormalities and $3(4.6 \%)$ were histologically normal. Logistic regression analysis accounting for the effects of other variables demonstrated a relationship between aortic root dilatation and male sex, aortic override greater than $50 \%$, presence of double-outlet right ventricle, elastic fragmentation, and increased ground substance. The predictive accuracy of logistic regression model on aortic root dilatation, as assessed by area under the ROC curve, was $92.4 \%$. Furthermore, the presence of a histologically abnormal aorta was associated with 15.97 times (95\% CI 3.07-83.15) higher risk of aortic dilatation as compared with normal aorta (Tables 1 and 2 and Figure 1).

In this study, there was a clear male predominance among patients with dilated aorta, even after indexing for body surface area and adapting for age from Roman and associates. ${ }^{14}$ Literature documents significantly greater aortic root size in healthy male compared with female patients. ${ }^{14,17}$ This was also the case in our patients with TOF undergoing repair. Aortic elasticity and distensibility are known to decline with age, especially among male patients. ${ }^{15,17}$ This may explain in part the male predominance among patients with aortic dilatation.

Histologic changes in the aortic media of patients with TOF resemble those observed in both bicuspid aortic valve disease and Marfan syndrome. ${ }^{15,16,21}$ Whether these changes result from a primary or intrinsic medial abnormality inherent in TOF itself or are secondary to the antecedent volume-overloaded aorta before repair remains unknown. Warnes and Child ${ }^{13}$ have postulated that a combination of intrinsic capacity for premature cellular injury or cell death and programmed stress-induced activation of tissue enzymes might be the causative factors for such apoptotic medial changes in TOF. ${ }^{18-20}$

Alternatively, there may be one or more cellular abnormalities of the aorta in patients with conotruncal abnormalities. During embryogenesis, occipital neural crest cells derived from cranial neural fold migrate into the cardiac outflow tract and participate in outflow tract septation. 22,23 These neuroectodermal immigrants into the ascending aorta in patients with conotruncal abnormalities may influence medial degeneration and aortic dilatation. ${ }^{22,23}$ On the basis of these observations, Niwa and associates ${ }^{8-10}$ postulated that patients with TOF may harbor an aortic wall abnormality that reflects a common developmental fault that weakens and attenuates the aortic wall.

In this study, the presence of aortic root dilatation in early infancy and the occurrence of intrinsic aortopathy in patients as early as 6 months of age strongly suggest that intrinsic aortic wall abnormalities also play a causative role in aortic root dilatation, in addition to the effects of volume overloading and physiologic changes associated with ageing.

\section{When Should Aortic Root Replacement Be Considered in Patients With Dilated Aortic Root? Should the Same Criteria Be Used as Are Used for Marfan Syndrome?}

Published literature including our observations in this study do not provide any conclusive answer. ${ }^{1,3,6-8,10,12,13}$ However, if patients are reoperated on for aortic or pulmonary valve replacement, it would appear prudent to consider concomitant aortic root repair or replacement if the aortic root is more than $50 \mathrm{~mm}$ in diameter. ${ }^{8,10,24}$ There is no current consensus on which patients and at what stage of aortic root dilatation isolated aortic root surgery should be considered in the absence of other indications for operation. Nor there is any consensus on $\beta$-blocker administration for 
limiting aortic root dilatation in patients who underwent intracardiac repair. ${ }^{24}$

In this series, of 65 patients with dilated aorta, $13(20 \%)$ patients had trivial to mild aortic regurgitation. None of them required aortic root repair/replacement at the time of intracardiac repair. These patients are being followed up with 2-dimensional and Doppler echocardiogram and magnetic resonance imaging for serial assessment of aortic root size and quantification of aortic regurgitation. To this point, none of them has aortic regurgitation or aortic root dilatation severe enough to necessitate aortic valve or aortic root surgery. In a Mayo Clinic series, the largest aortic root measured was $85 \mathrm{~mm}$ in diameter without dissection. ${ }^{7} \mathrm{On}$ the other hand, literature documents 2 isolated reports of aortic dissection with aortic root diameter measuring 6.45 $\mathrm{cm}$ and $6.1 \mathrm{~cm}$, respectively. ${ }^{25,26}$

\section{Evaluation and Analyses of Risk Factors for Development of Histologic Abnormalities (Elastic Fragmentation, Accumulation of Ground Substance, Medionecrosis, Smooth Muscle Disarray, and Fibrosis) in the Aortic Wall of TOF}

The normal aortic media consists of layers of longitudinally arranged elastic lamellae interspersed with smooth muscle cells and collagen fibrils in a mucopolysaccharide ground substance. Each lamella and the adjacent zone containing the smooth muscle cells synthesize the connective tissue matrix and form a lamellar unit (Figure E1, $A$ and $B$ ). The parallel elastic lamellae are more numerous in the ascending aorta, usually 55 units, and decrease in number across the descending thoracic aorta. ${ }^{27}$ The media is not a static structure. The number of elastic lamellae is only 35 at birth; by adult life, it is $55 .{ }^{27} \mathrm{With}$ increasing age, the elastic lamellae reduplicate and there is a corresponding decrease and degeneration of elastic lamellae and partial replacement with collagen, resulting eventually in the aforementioned histologic changes.

In our study, elastic fragmentation and fibrosis seemed to occur in greater proportion among patients with TOF across all age groups in comparison with changes like medionecrosis, which was more prevalent in patients undergoing previous palliative systemic-pulmonary arterial shunts, higher RVEDP, increased indexed aortic diameter, and the presence of MAPCAs (Table 3).

Another important finding of this investigation is the close interrelationship between lamellar loss and appearance of histopathologic changes. A mean lamellar count of 40.85 was always associated with a histologically abnormal aorta and aortic dilatation ( $\mathrm{OR}=7.46[95 \% \mathrm{CI}=2.84$ 19.58]; $P<.0001$ ). A lamellar count of less than 60 was associated with a sensitivity of $80 \%$ and a specificity of $87.6 \%$. The predictive value of a positive or negative result was $68.7 \%$ and $92.3 \%$, respectively. Area analysis under the ROC curve indicated that $93.37 \%$ (SE \pm 0.039 ) of the time, the value of lamellar count was lower for the abnormal histopathology group compared with normal (Table 2, Figure 2).

Patients aged more than 96 months, systemic arterial desaturation less than $80 \%$, having aortic override of more than $50 \%$, indexed aortic diameter of more than $24.80 \mathrm{~mm}$, and presence of MAPCAs were the significant risk factors for the development of elastic fragmentation by logistic regression analysis (Table 3). Thus, this study revealed earlier and frequent occurrence of lamellar loss, elastic fragmentation, and disruption in patients with TOF. Elastin has a long half-life of 40 to 70 years, and the loss of elastin in adults is most likely a manifestation of elastolysis rather than insufficient synthesis. ${ }^{21}$ In children with TOF and pulmonary stenosis/pulmonary atresia, whether the loss of elastin is due to increased elastolysis stimulated by the shear and increased flow volume through the aorta or due to intrinsic problems of elastin synthesis remains uncertain. ${ }^{12}$ It is hypothesized that this intrinsic abnormality may be an expression of a hitherto unrecognized genetic defect involving the cellular function in the aortic media of patients with TOF, or may be programmed cell death. ${ }^{8-13,18-20}$

Apoptosis is programmed cell death, not increased or premature destruction of extracellular matrix proteins, that is, elastic fibers. If apoptosis of smooth muscle cells is the underlying mechanism for bicuspid aortopathy, could the elastic fragmentation and disruption seen in our patients with TOF be the final expression of elastolysis of the fibers? The obvious triggering factor here would be the shearing force from volume-overloaded aorta early in life, with the greatest stress being generated at the aortic root and ascending aorta.

\section{Comparison of Patients Younger Than 2 Years of Age With Those Over 14 Years}

As late presentation of congenital heart disease is not unusual in the developing world, it is not uncommon to be faced with the grown-up patient with TOF physiology without previous palliation. They are more cyanotic and polycythemic and are indeed a different subset from those encountered in the Western world. Only $11(11.2 \%)$ patients in this series undergoing intracardiac repair were between 6 and 24 months of age. Despite the median age of just under 6 years in this study group, only about a third of the patients $(28.5 \%)$ were shunted. Although our setting is a tertiary care center, the socioeconomic profile of the patients and the lack of health care insurance benefit led to delayed referral and surgery, accounting for higher age of the patients.

The 2 groups of patients in this study population represent the extremes of age ( $<2$ years and $>14$ years) and of morphologic alterations. Although severe degenerative changes ranging from grade 3 elastic fragmentation to medionecrosis and fibrosis were present in patients aged more than 14 years, similar changes were observed in a subset of 
patients under 2 years of age. The additional adverse effects of systemic arterial desaturation $(<80 \%)$, higher hematocrit $(>45 \%)$, aortic override $(>50 \%)$, increased indexed aortic diameter $\left(>24.80 \mathrm{~mm} / \mathrm{m}^{2}\right)$, higher RVEDP $(>12 \mathrm{~mm} \mathrm{Hg})$, presence of right aortic arch, double-outlet right ventricle, and pulmonary atresia might be expected to influence the development of early degenerative process.

Thus, our study shows a statistically significant interrelationship between lamellar loss and the appearance of histopathologic changes in the aortic wall of patients with TOF. These histologic abnormalities possibly reduce the cohesive and tensile strength of the media and suggest an important causative mechanism for aortic root dilatation.

\section{Study Limitations}

The principal limitation of this study is its sample size. Degenerative changes in the aortic wall are a complex and variable process. With the current techniques to assess degenerative changes, a prohibitively high number of samples are required to determine the extent of this problem and its correlation with various clinical entities. The second limitation is that we examined histologically only a small segment of the ascending aorta.

Thirdly, the aorta is volume overloaded in TOF, with the greatest stress being generated at the aortic root and ascending aorta. The tissue samples in this study were obtained from the aortic cannulation site and not from the aortic sinuses because this could cause further destruction of the aortic sinuses.

Fourth, it remains uncertain whether these medial abnormalities in the ascending aorta, even in infants and young children, are inherent or acquired. Finally, whether the loss of elastin is an expression of a hitherto unrecognized genetic defect involving the cellular function or apoptosis remains uncertain.

Larger scale clinical studies of the aorta commencing in infancy are required and may shed further light on the risk stratification for aortic dilatation and the rate of its progression.

\section{Clinical Implications and Recommendations}

The present study indicates preponderance of degenerative changes in the aortic tissue of adult TOF, in patients with long-standing cyanosis and pressure overload, increased aortic dimensions, right aortic arch, and in patients with raised RVEDP, and it supports the concept of early operative correction if technically appropriate. These observations serve to emphasize that patients undergoing intracardiac repair require meticulous life-long follow-up. Comprehensive assessment should include a clinical and echocardiographic evaluation not only of the right ventricular outflow tract but also of the aorta.
The present impetus to operate on these patients early in life might mean that aortic root dilatation might be a pathologic condition of the past and not of future generations of patients with TOF.

Early surgical repair of these patients may prevent right ventricular dilatation and fibrosis by decreasing the volume and pressure overload. Thus, even if there is an intrinsic developmental tendency to medial disease, limiting the exposure to hemodynamic stress may obviate future aortic dilatation as well as progression of aortic regurgitation. Nevertheless, the range, prevalence, degree, and potential cardiac surgical risk posed by these abnormalities are matters that warrant emphasis.

\section{Conclusions}

We conclude that there are marked histopathologic changes ranging from loss and fragmentation of elastic lamellae, increased accumulation of ground substance, medionecrosis, and muscle disarray to fibrosis in patients with TOF. These medial abnormalities may provide the substrate for subsequent progressive aortic dilatation and warrant further investigation.

Progressive aortic dilatation with aortic regurgitation can occur despite early repair of TOF. The deterioration may take a long time to develop, which emphasizes the need for continued and life-long follow-up of all patients after intracardiac repair.

The authors are grateful to Mr Shankar Sharma for preparation of the manuscript.

\section{References}

1. Ricker RP, Berman MA, Stansel HC Jr. Postoperative studies in patients with tetralogy of Fallot. Ann Thorac Surg. 1975;19:17-25.

2. Marelli AJ, Perloff JK, Child JS, Laks H. Pulmonary atresia with ventricular septal defect in adults. Circulation. 1994;89:243-51.

3. Niwa K, Siu SC, Webb G, Gatzoulis M. Progressive aortic root dilatation in adults late after repair of tetralogy of Fallot. Circulation. 2002;106:1374-8.

4. Capelli H, Ross D, Somerville J. Aortic regurgitation in tetrad of Fallot and pulmonary atresia. Am J Cardiol. 1982;49:1979-83.

5. Chugh R, Child JS, Perloff JK, et al. Echocardiographic characterization of the aortic root in adults with tetralogy of Fallot (abstract) Circulation. 2001;104(Suppl):II558.

6. Matsuda H, Ihara K, Mori T, Kitamura S, Kawashima Y. Tetralogy of Fallot associated with aortic insufficiency. Ann Thorac Surg. 1980;29: 529-33.

7. Dodds GA III, Warnes CA, Danielson GK. Aortic valve replacement after repair of pulmonary atresia and ventricular septal defect or tetralogy of Fallot. J Thorac Cardiovasc Surg. 1997;113:736-41.

8. Niwa K, Perloff JK, Bhuta SM, Miner PD, Drinkwater D, Laks H. Light and electron microscopy of dilated great arteries in congenital heart disease. J Am Coll Cardiol. 1997;29:1065-73.

9. Niwa K, Perloff JK, Bhuta SM, Laks H, Drinkwater DC, Child JS, et al. Structural abnormalities of great arterial walls in congenital heart disease: light and electron microscopic analyses. Circulation. 2001; 103:393-400.

10. Niwa K Aortic root dilatation in tetralogy of Fallot long-term after repair-histology of the aorta in tetralogy of Fallot: evidence of intrinsic aortopathy. Int J Cardiol. 2005;103:117-9. 
11. Zecchel R, Ho SY, Davlouros PA, Gatzoulis MA. Histology of the aorta, and aortic root dilatation in adults with tetralogy of Fallot. J Am Coll Cardiol. 2001:37:468A.

12. Tan LJ, Davlouros AP, McCarthy PK, Gatzoulis AM, Ho SY. Intrinsic histological abnormalities of aortic root and ascending aorta in tetralogy of Fallot: evidence of causative mechanism for aortic dilatation and aortopathy. Circulation. 2005;112:961-8.

13. Warnes CA, Child JS. Aortic root dilatation after repair of tetralogy of Fallot: pathology from the past. Circulation. 2002;106:1310-1.

14. Roman MJ. Devereux RB, Kramer-Fox R, O’Loughlin J. Two-dimensional echocardiographic aortic root dimensions in normal children and adults. Am J Cardiol. 1989;64:507-12.

15. Schlatmann TJ, Becker AE. Histologic changes in the normal aging aorta: implications for dissecting aortic aneurysm. Am J Cardiol. 1977;39:13-20.

16. de Sa M, Moshkovitz Y, Butany J, David TE. Histologic abnormalities of the ascending aorta and pulmonary trunk in patients with bicuspid aortic value disease: clinical relevance to the Ross procedure. J Thorac Cardiovasc Surg. 1999;118:588-96.

17. Vasan RS, Larson MR, Levy D. Determinations of echocardiography aortic root size: the Framingham heart Study. Circulation. 1995;89: 734-40.

18. Schwartz LM, Smith SW, Jones MEE, Osborne BA. Do all programmed cell deaths occur via apoptosis? Proc Natl Acad Sci U S A. 1993;90:980-4.
19. Steller H. Mechanisms and genes of cellular suicide. Science. 1995; 267:1445-9.

20. Buja LM, Eigenbrodt ML, Eigenbrodt EH. Apoptosis and necrosis: basic types and mechanisms of cell death. Arch Pathol Lab Med. 1993;117:1208-14.

21. Shah PK. Inflammation, metalloproteinases and increased proteolysis as emerging pathophysiological paradigm in aortic aneurysm. Circulation. 1997;96:2115-7.

22. Kirby ML, Gale TF, Stewart DE. Neural crest cells contribute to normal aorticopulmonary septation. Science. 1983;220:1059-61.

23. Rosenquist TH, Beall AC, Modis L, Fishman R. Impaired elastic matrix development in the great arteries after ablation of the cardiac neural crest. Anat Rec. 1990;226:347-59.

24. Therrien J, Gatzoulis M, Graham T, Bink-Boelkens M, Connelly M, Niwa K, et al. CCS Consensus Conference 2001 update: recommendations for the management of adults with congenital heart diseasepart II. Can J Cardiol. 2001;17:1029-50.

25. Kim WH, Seo JW, Kim SJ, Song J, Lee J, Na CY. Aortic dissection late after repair of tetralogy of Fallot. Int J Cardiol. 2005;101:515-6.

26. Rathi VK. Doyle M, Williams RB, Yamrozik J, Shannon RP, Biederman RW. Massive aortic aneurysm and dissection in repaired tetralogy of Fallot: diagnosis by cardiovascular magnetic resonance imaging. Int J Cardiol. 2005;101:169-70.

27. Wolinsky H. Comparison of medial growth of human thoracic and abdominal aortas. Circ Res. 1970;27:531-8.

\section{The Journal of Thoracic and Cardiovascular Surgery Conflict of Interest Policy}

To assure fairness to authors submitting work for consideration in The Journal of Thoracic and Cardiovascular Surgery, a mechanism exists for managing conflicts of interest. The editor and each of the section editors complete a "Conflict of Interest" form that identifies any and all relationships with commercial and other academic entities. When the editor has a potential conflict because of a relationship with another entity or author, the editor appoints an alternate editor from among the section editors or editorial board members who assumes the entire responsibility for final decisions on the manuscript in question. The editor does not read the reviews that are submitted nor engage in discussing the manuscript prior to the final decision. When the conflict of interest involves a section editor, a "guest section editor" is appointed who fills the role normally played by the conflicted section editor. All members of the editorial board and reviewers are asked to indicate any conflict of interest when they agree to review a manuscript. 
TABLE E1. Demographic, operative and postoperative details of the study group

\begin{tabular}{|c|c|}
\hline Patient-related variables & Mean \pm SD (range) \\
\hline Age at operation (mo) & $104.5 \pm 102.72$ (6 mo-47 y; median $72 \mathrm{mo})$ \\
\hline \multicolumn{2}{|l|}{ Age } \\
\hline$<96$ mo & 65 \\
\hline$>96$ mo & 33 \\
\hline Male/female & $71: 27$ \\
\hline Weight at operation $(\mathrm{kg})$ & $21.42 \pm 14.76(2.5-80 \mathrm{~kg} ;$ median 16 kg) \\
\hline Body surface area $\left(\mathrm{m}^{2}\right)$ & $0.81 \pm 0.38\left(0.19-2.0 \mathrm{~m}^{2} ;\right.$ median $\left.0.75 \mathrm{~m}^{2}\right)$ \\
\hline Previous Blalock-Taussig shunt & 28 \\
\hline Preoperative hemoglobin ( $\mathrm{g} / \mathrm{dL})$ & $14.8 \pm 4.8(14-25)$ \\
\hline \multicolumn{2}{|l|}{ Preoperative hematocrit value } \\
\hline$<45 \%$ & 41 \\
\hline$>45 \%$ & 57 \\
\hline \multicolumn{2}{|l|}{ Preoperative right ventricular end-diastolic pressure } \\
\hline$<12 \mathrm{~mm} \mathrm{Hg}$ & 81 \\
\hline$>12 \mathrm{~mm} \mathrm{Hg}$ & 17 \\
\hline \multicolumn{2}{|l|}{ Preoperative systemic arterial oxygen saturation (\%) } \\
\hline$<80 \%$ & 51 \\
\hline$>80 \%$ & 47 \\
\hline Coil embolization of MAPCAs & 34 \\
\hline Right aortic arch & 22 \\
\hline \multicolumn{2}{|l|}{ Aortic override } \\
\hline$>50 \%$ & 42 \\
\hline$<50 \%$ & 56 \\
\hline Indexed aortic diameter $\left(\mathrm{mm} / \mathrm{m}^{2}\right)$ & $26.23 \pm 10.81(0-70 ;$ median 24.80$)$ \\
\hline \multicolumn{2}{|l|}{ Dilated aortic root } \\
\hline Preoperative & 65 \\
\hline Postoperative & 65 \\
\hline \multicolumn{2}{|l|}{ Aortic regurgitation } \\
\hline Yes & 13 \\
\hline No & 85 \\
\hline \multicolumn{2}{|l|}{ Diagnosis } \\
\hline TOF with pulmonary stenosis & 56 \\
\hline DORV (Fallot type) and TOF with pulmonary atresia & 42 \\
\hline Lowest temperature at operation & $28^{\circ} \mathrm{C}$ \\
\hline Aortic crossclamp time (min) & $40.0 \pm 15.0$ \\
\hline Preoperative peak systolic pressure ratio (PRV/LV) & $0.98 \pm 0.04$ \\
\hline Postoperative peak systolic pressure ratio (PRV/LV) & $0.42 \pm 0.16$ \\
\hline Postoperative mean PA pressure $(\mathrm{mm} \mathrm{Hg})$ & $15.6 \pm 3.2$ \\
\hline
\end{tabular}

$S D$, Standard deviation; MAPCA, major aortopulmonary collateral artery; TOF, tetralogy of Fallot; $D O R V$, double-outlet right ventricle; $L V$, left ventricle; $R V$, right ventricle; $P A$, pulmonary artery. 
TABLE E2. Histologic definitions and grading of tunica media sections of the aortic wall

\begin{tabular}{|c|c|c|c|}
\hline Histologic definition & Grade 1 & Grade 2 & Grade 3 \\
\hline \multicolumn{4}{|l|}{ Medionecrosis } \\
\hline $\begin{array}{l}\text { Focal loss of smooth muscle } \\
\text { cell nuclei media }\end{array}$ & $\begin{array}{l}\text { Focal loss consisting of }< \\
\text { one third of total width } \\
\text { of media }\end{array}$ & $\begin{array}{l}\text { Focal loss consisting of one } \\
\text { third to two thirds of } \\
\text { media thickness }\end{array}$ & $\begin{array}{l}\text { Focal loss consisting of }>\text { two } \\
\text { thirds of media thickness }\end{array}$ \\
\hline \multicolumn{4}{|c|}{ (1) } \\
\hline $\begin{array}{l}\text { Increases in interstitial } \\
\text { collagen }\end{array}$ & $\begin{array}{l}\text { Fibrosis in }<\text { one third of } \\
\text { total width of media or } \\
\text { focal accumulation } \\
\text { throughout }\end{array}$ & $\begin{array}{l}\text { Fibrosis in one third to two } \\
\text { thirds of total width of } \\
\text { media with multiple small } \\
\text { areas of fibrosis }\end{array}$ & $\begin{array}{l}\text { Fibrosis in }>\text { two thirds of } \\
\text { total width of media with } \\
\text { multiple small areas of } \\
\text { fibrosis }\end{array}$ \\
\hline \multicolumn{4}{|l|}{$\begin{array}{l}\text { Cystic medial necrosis } \\
\text { (mucoid accumulation) }\end{array}$} \\
\hline $\begin{array}{l}\text { Cysts are observed in } \\
\text { presence of intact elastic } \\
\text { lamellae and fragmented } \\
\text { elastic fibers }\end{array}$ & $\begin{array}{l}\text { Minute foci within a } \\
\text { single lamellar unit not } \\
\text { encompassing its entire } \\
\text { width }\end{array}$ & $\begin{array}{l}\text { Increased size and No. of } \\
\text { "cysts" plus mucoid } \\
\text { material covering the } \\
\text { total width of } 1 \text { lamellar } \\
\text { unit }\end{array}$ & $\begin{array}{l}\text { Large and extended "cysts" } \\
\text { (>1 lamellar unit) with } \\
\text { fragmentation of elastic } \\
\text { fibers }\end{array}$ \\
\hline \multicolumn{4}{|l|}{ Elastic fragmentation } \\
\hline $\begin{array}{l}\text { Focal fragmentation of elastic } \\
\text { lamellae in aortic media }\end{array}$ & $\begin{array}{l}<5 \text { foci of elastic } \\
\text { lamellae fragmentation } \\
\text { in } 1 \text { microscopic field of } \\
\times 200\end{array}$ & $\begin{array}{l}\text { 5-9 foci of elastic lamellae } \\
\text { fragmentation in } 1 \\
\text { microscopic field of } \times 200\end{array}$ & $\begin{array}{l}\geq 10 \text { foci of elastic lamellae } \\
\text { fragmentation in } 1 \\
\text { microscopic field of } \times 200\end{array}$ \\
\hline Elastic lamellae & $\begin{array}{l}\text { Total No. of elastic } \\
\text { lamellae in media were } \\
\text { counted. Median value } \\
\text { in different age groups } \\
\text { was used as the } \\
\text { "cutoff" value to } \\
\text { differentiate normal } \\
\text { from abnormal }\end{array}$ & & \\
\hline
\end{tabular}


TABLE E3. Odds ratio for potential risk factors for aortic dilatation in patients undergoing intracardiac repair of TOF (bivariate analysis) $(\mathbf{n}=98)$

\begin{tabular}{|c|c|c|c|c|c|}
\hline \multirow[b]{2}{*}{ Serial No. } & \multirow[b]{2}{*}{ Variables } & \multicolumn{3}{|c|}{ Aortic dilatation } & \multirow[b]{2}{*}{$P$ value } \\
\hline & & No. & No. $(\%)$ & OR $(95 \% \mathrm{CI})$ & \\
\hline \multirow[t]{3}{*}{1.} & Aortic wall histology & & & & \\
\hline & - Abnormal & 73 & 62 & $41.33(10.54-162.02)$ & $<.001$ \\
\hline & - Normal control & 25 & 3 & & \\
\hline \multirow[t]{3}{*}{2.} & Elastic fragmentation & & & & \\
\hline & - Present & 73 & 62 & $41.33(10.54-162.02)$ & $<.001$ \\
\hline & - Absent & 25 & 3 & & \\
\hline \multirow[t]{3}{*}{3.} & Increased ground substance & & & & \\
\hline & - Present & 53 & 49 & $22.21(6.77-72.83)$ & $<.001$ \\
\hline & - Absent & 45 & 16 & & \\
\hline \multirow[t]{3}{*}{4.} & Medionecrosis & & & & \\
\hline & - Present & 39 & 31 & $2.85(1.12-7.25)$ & .028 \\
\hline & - Absent & 59 & 34 & & \\
\hline \multirow[t]{3}{*}{5.} & Muscle disarray & & & & \\
\hline & - Present & 26 & 22 & $3.97(1.24-12.69)$ & .02 \\
\hline & - Absent & 72 & 43 & & \\
\hline \multirow[t]{3}{*}{6.} & Fibrosis & & & & \\
\hline & - Present & 56 & 50 & $15.0(5.21-43.13)$ & $<.001$ \\
\hline & - Absent & 42 & 15 & & \\
\hline \multirow[t]{3}{*}{7.} & Age & & & & \\
\hline & - >96 mo & 33 & 31 & $14.13(3.12-63.99)$ & $<.001$ \\
\hline & - $<96 \mathrm{mo}$ & 65 & 34 & & \\
\hline \multirow[t]{3}{*}{8.} & Sex & & & & \\
\hline & - Male & 71 & 58 & $12.74(4.46-36.42)$ & $<.001$ \\
\hline & - Female & 27 & 7 & & \\
\hline \multirow[t]{3}{*}{9.} & Systemic arterial oxygen saturation & & & & \\
\hline & - $<80 \%$ & 51 & 44 & $7.78(2.91-20.80)$ & $<.001$ \\
\hline & - $>80 \%$ & 47 & 21 & & \\
\hline
\end{tabular}


TABLE E3. Continued

\begin{tabular}{|c|c|c|c|c|c|}
\hline \multirow[b]{2}{*}{ Serial No. } & \multirow[b]{2}{*}{ Variables } & \multicolumn{3}{|c|}{ Aortic dilatation } & \multirow[b]{2}{*}{$P$ value } \\
\hline & & No. & No. $(\%)$ & OR (95\% Cl) & \\
\hline \multirow[t]{3}{*}{10.} & Hematocrit & & & & \\
\hline & - $>45 \%$ & 57 & 43 & $2.65(1.12-6.27)$ & .02 \\
\hline & - $<45 \%$ & 41 & 22 & & \\
\hline \multirow[t]{3}{*}{11.} & Aortic override & & & & \\
\hline & - $>50 \%$ & 42 & 40 & $19.16(5.45-112.79)$ & $<.001$ \\
\hline & - $<50 \%$ & 56 & 25 & & \\
\hline \multirow[t]{3}{*}{12.} & Aortic regurgitation & & & & \\
\hline & - Yes & 13 & 12 & $7.24(0.89-58.38)$ & .06 \\
\hline & - No & 85 & 53 & & \\
\hline \multirow[t]{3}{*}{13.} & MAPCAs & & & & \\
\hline & - Present & 34 & 29 & $3.62(1.31-9.96)$ & .01 \\
\hline & - Absent & 64 & 36 & & \\
\hline \multirow[t]{3}{*}{14.} & Previous palliation & & & & \\
\hline & - Yes & 28 & 20 & $1.38(0.53-3.61)$ & .5 \\
\hline & - No & 70 & 45 & & \\
\hline \multirow[t]{3}{*}{15.} & Right ventricular end-diastolic pressure & & & & \\
\hline & $\bullet>12 \mathrm{~mm} \mathrm{Hg}$ & 17 & 16 & $10.45(1.32-82.69)$ & .02 \\
\hline & $\bullet<12 \mathrm{~mm} \mathrm{Hg}$ & 81 & 49 & & \\
\hline \multirow[t]{3}{*}{16.} & Right aortic arch & & & & \\
\hline & - Yes & 22 & 19 & $4.13(1.12-15.18)$ & .03 \\
\hline & - No & 76 & 46 & & \\
\hline \multirow[t]{3}{*}{17.} & Diagnosis & & & & \\
\hline & • TOF with PS & 56 & 28 & $7.4(2.53-21.59)$ & $<.001$ \\
\hline & - DORV, TOF with PA & 42 & 37 & & \\
\hline \multirow[t]{3}{*}{18.} & Lamellar count & & & & \\
\hline & - Abnormal (mean \pm SD $40.85 \pm 11.05$; range $15-59$ ) & 73 & 62 & $7.46(2.84-19.58)$ & $<.001$ \\
\hline & - Normal (mean \pm SD $66.72 \pm 4.69$; range $60-76)$ & 25 & 3 & & \\
\hline
\end{tabular}

OR, Odds ratio; TOF, tetralogy of Fallot; $C l$, confidence interval; $P S$, pulmonary stenosis; DORV, double-outlet right ventricle; $P A$, pulmonary atresia; $S D$, standard deviation. 
TABLE E4. Odds ratio for potential risk factors for elastic fragmentation, increased ground substance, medionecrosis, muscle disarray, and fibrosis in aortic tissue of TOF (bivariate analysis)

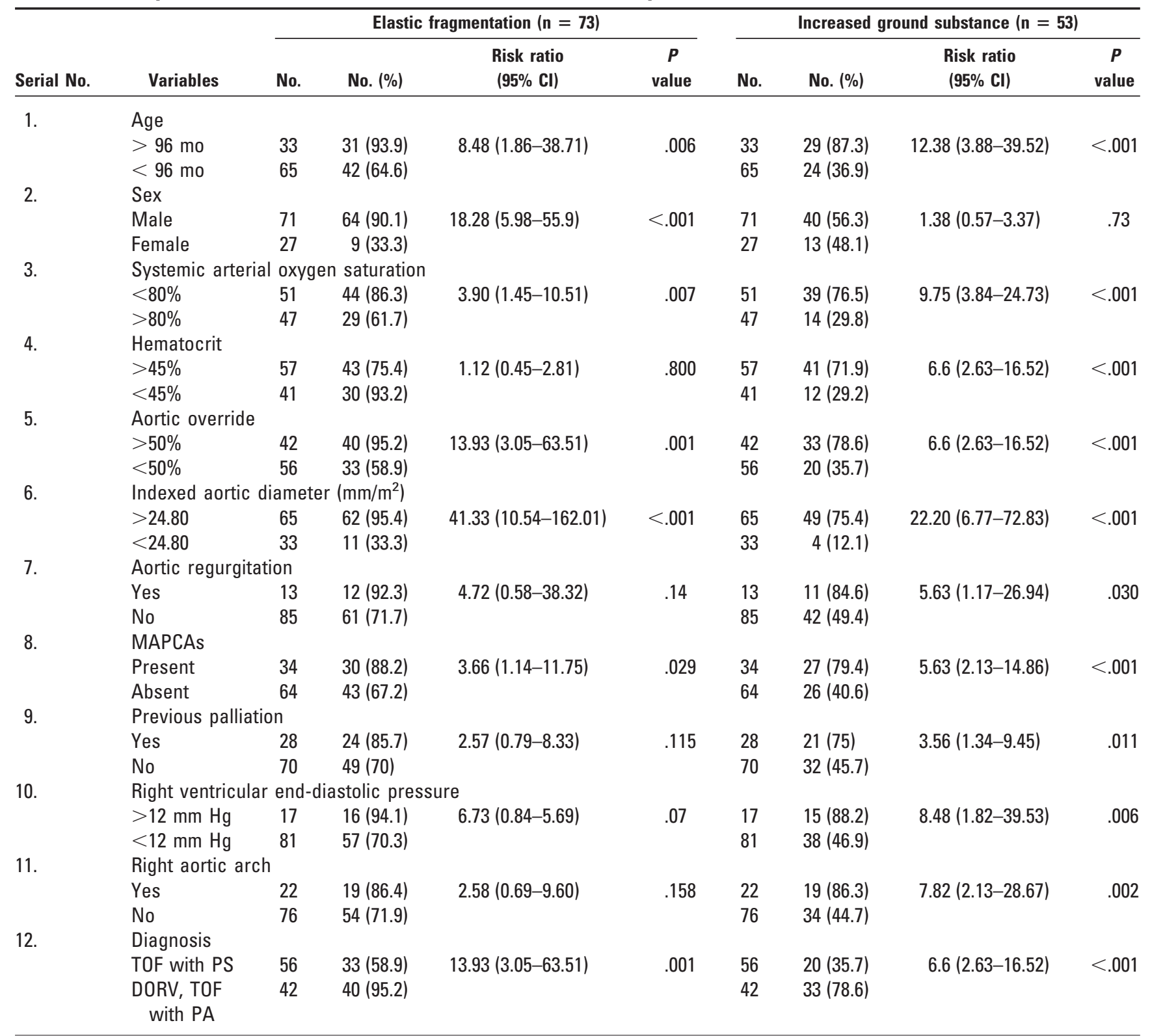

TOF, Tetralogy of Fallot; $\mathrm{Cl}$, confidence interval; MAPCA, major aortopulmonary collateral artery; $P S$, pulmonary stenosis; DORV, double-outlet right ventricle; $P A$, pulmonary atresia. 
TABLE E4.

(Continued)

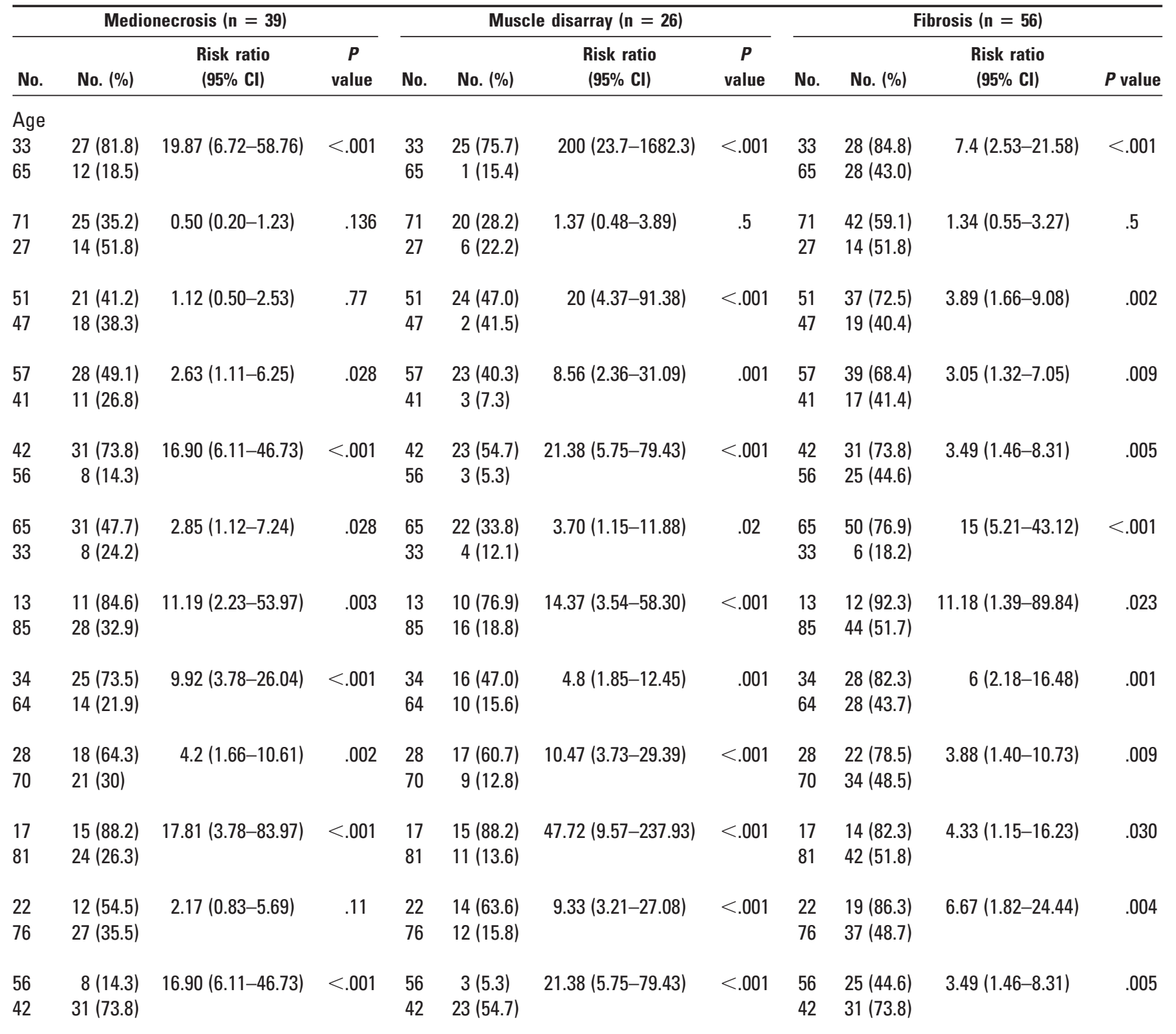

TOF, Tetralogy of Fallot; $\mathrm{Cl}$, confidence interval; MAPCA, major aortopulmonary collateral artery; PS, pulmonary stenosis; DORV, double-outlet right ventricle; $P A$, pulmonary atresia. 

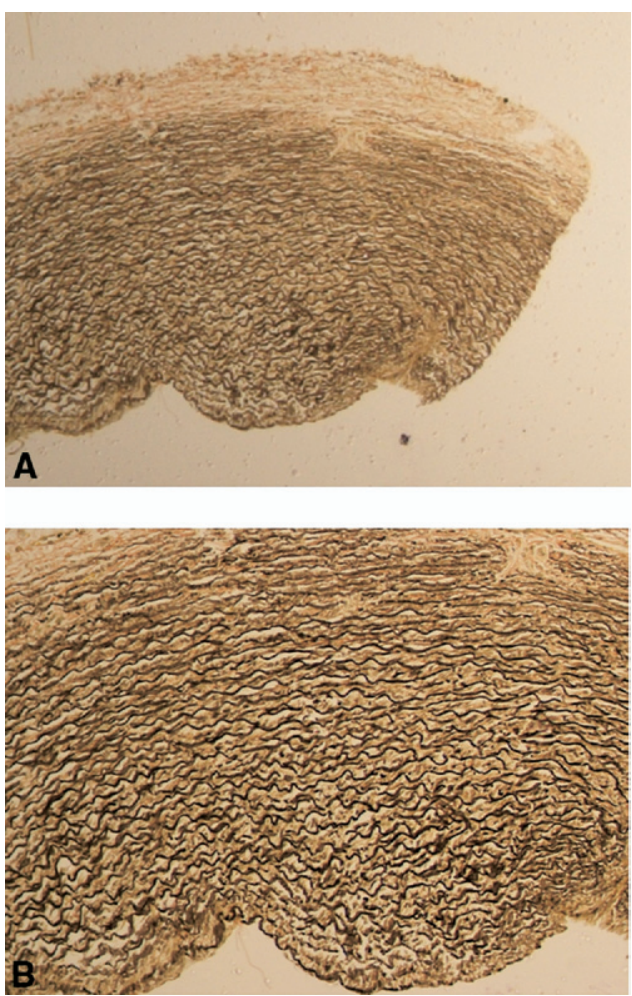

Figure E1. A and B, Photomicrographs of the ascending aortic biopsy specimen of a patient with tetralogy of Fallot (TOF) (light microscopy, elastic van Gieson stain $\times 40$ ) showing normal aortic media with corrugated, closely packed, longitudinally arranged intact elastic lamellae in a mucopolysaccharide ground substance.
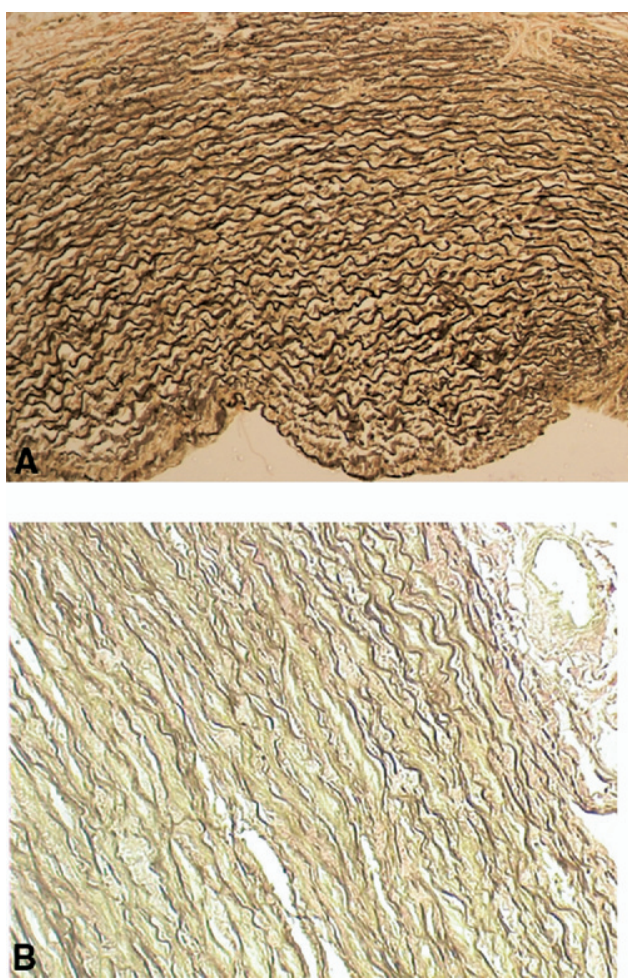

Figure E2. A and B, Photomicrographs of the ascending aorta of a patient with tetralogy of Fallot (TOF) (light microscopy $\times 100$, Verhoeff van Gieson stain) showing widespread lamellar loss and elastic tissue fragmentation (B) as compared with intact lamellae of a patient with normal aorta (A). 

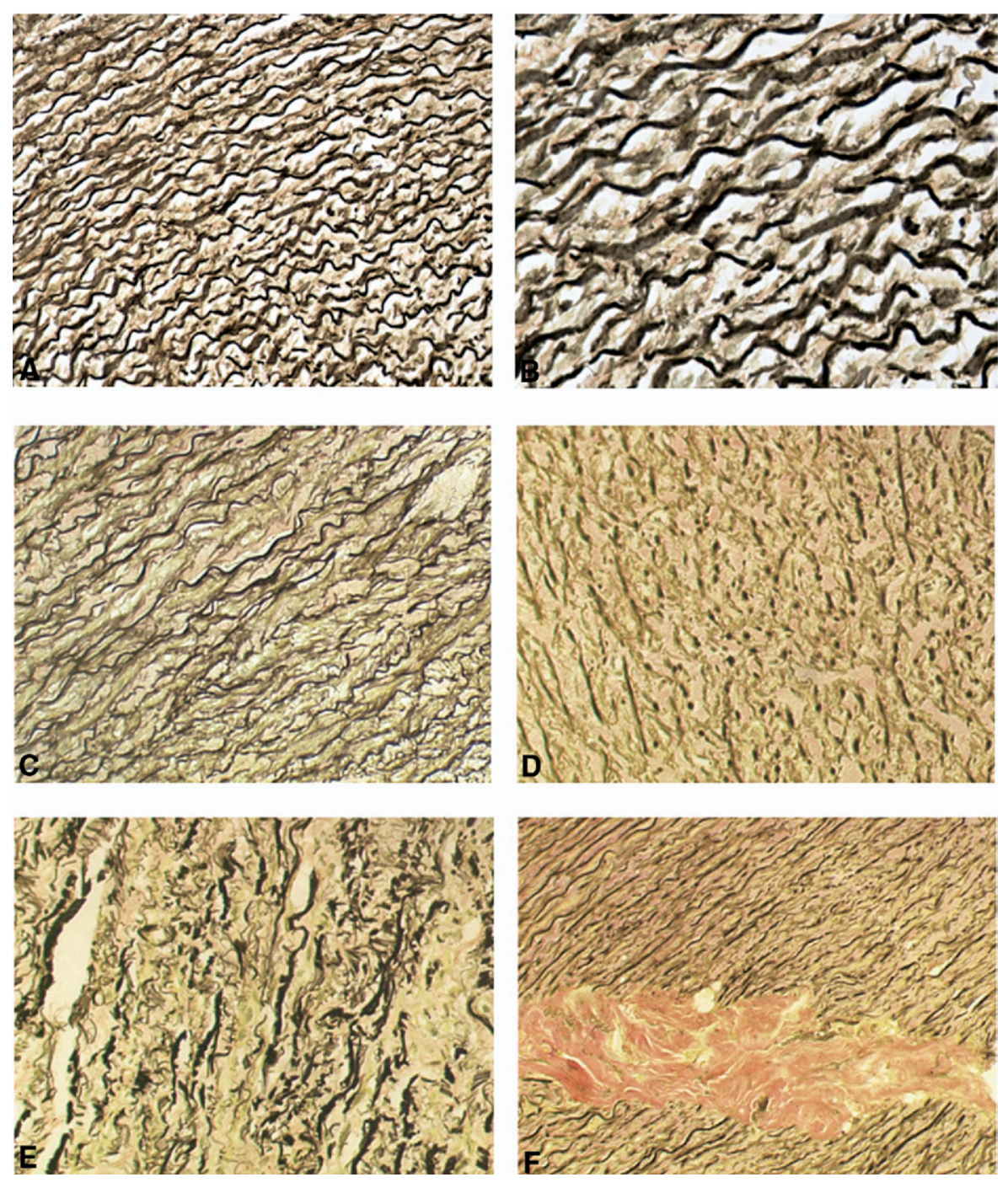

Figure E3. Photomicrographs of light microscopic biopsy from ascending aorta of patients with tetralogy of Fallot (TOF) (Verhoeff van Gieson stain $\times 100$ ) showing closely packed, longitudinally arranged, intact elastic lamellae of a normal aorta ( $A$ and $B$ ) and varying grades of elastic fiber fragmentation of abnormal aorta (C to F). C and $D$, Widespread elastic fiber fragmentation and lamellar loss with large areas of ground substance accumulation and loss of smooth muscle. F, Large area of fibrosis replacing the elastic lamellae. 

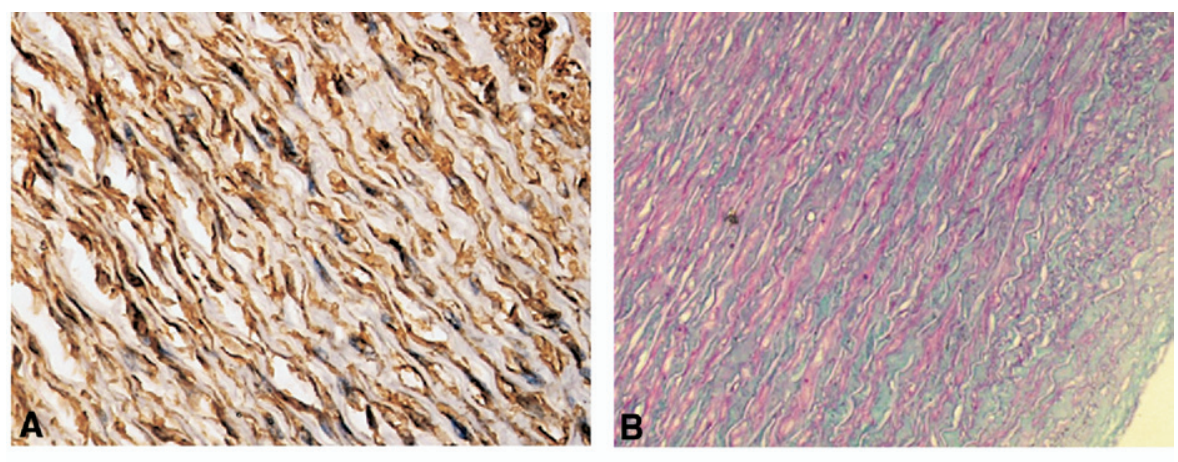

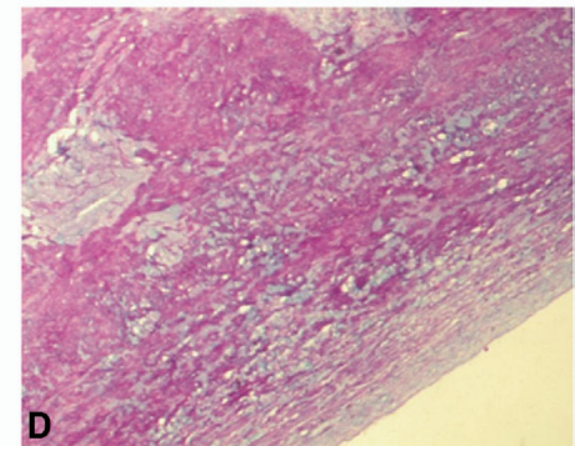

Figure E4. A to D, Photomicrographs of ascending aortic biopsy of patients with tetralogy of Fallot (TOF) (light microscopy, smooth muscle actin stain $\times 400[\mathrm{~A}]$; alcian blue periodic acidSchiff stain $\times 100$ [B to D]). $A$ and $B$, Normal aorta with layers of longitudinally arranged, elastic lamellae interspersed with smooth muscle cells and collagen fibrils in a mucopolysaccharide ground substance. $C$ and D, Disorganized media with loss of smooth muscle nuclei and varying grades of mucoid ground substance accumulation. D shows a large area of pools of mucopolysaccharides and collagen deposition. 

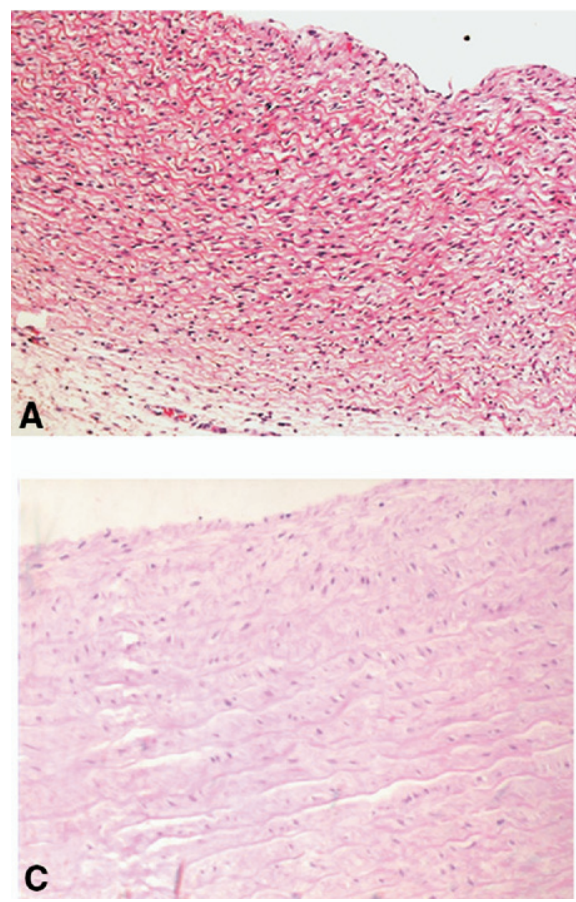
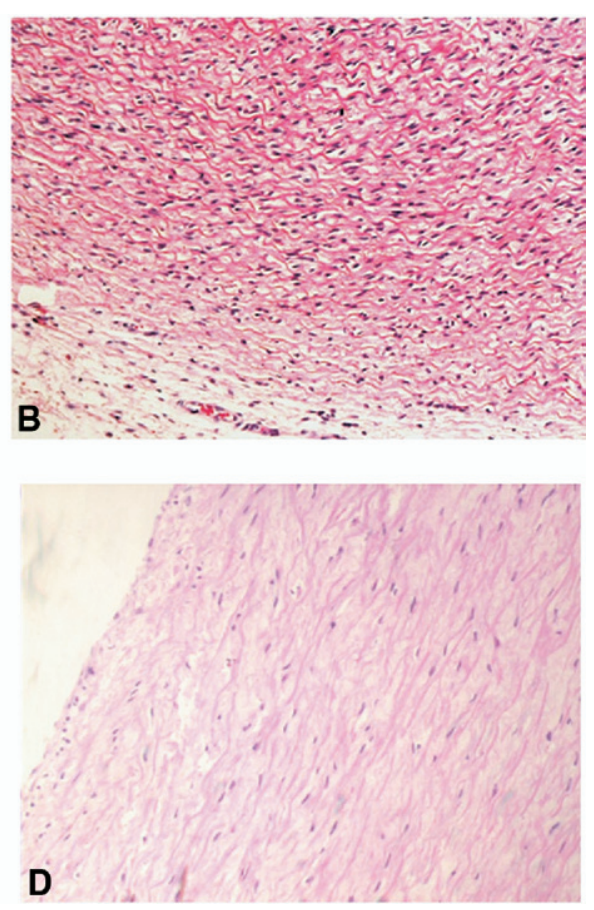

Figure E5. A to D, Photomicrographs from ascending aortic biopsy specimens of patients with tetralogy of Fallot (TOF) (light microscopy, hematoxylin and eosin stain $\times 100$ ) showing normal aortic media with layers of Iongitudinally arranged smooth muscle nuclei ( $A$ and $B$ ) and abnormal aorta with significant medial destruction and changes in smooth muscle orientation. 

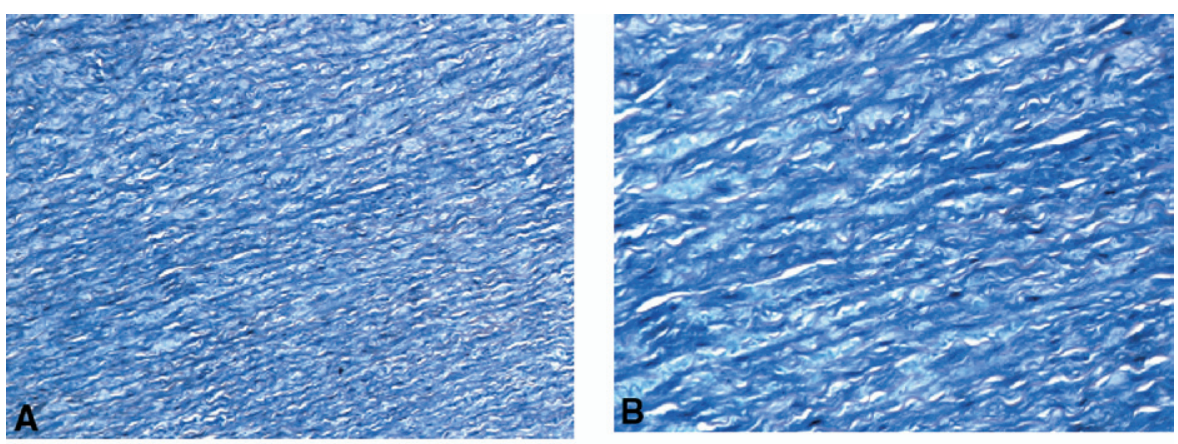

Figure E6. A to D, Photomicrographs from ascending aortic biopsy of patients with tetralogy of Fallot (TOF) (light microscopy, Masson trichrome stain $\times 100$ ). A and B, Closely packed, longitudinally arranged, intact elastic lamellae. C and D, Mild increase in fibrosis with increased interstitial collagen.
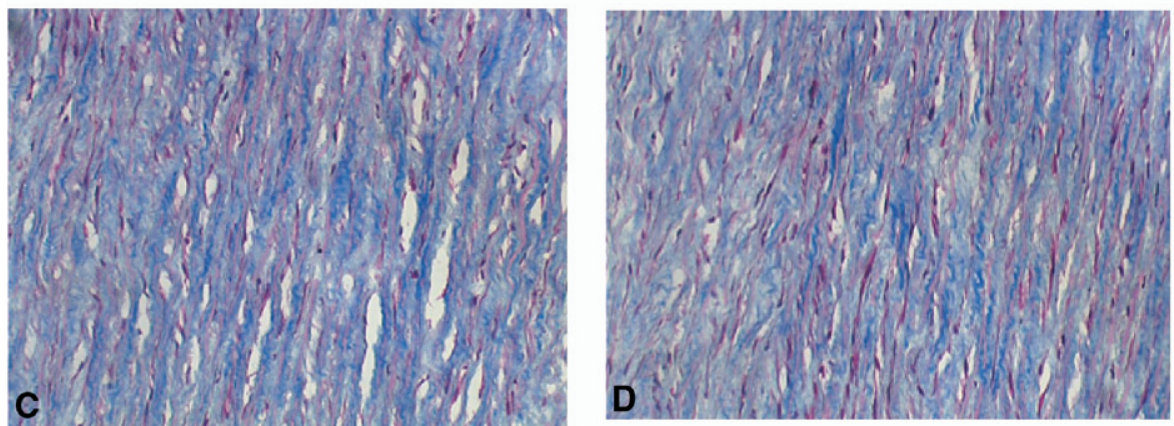